\title{
Models and Neural Bases of the Believing
} \section{Process}

\author{
Motoaki Sugiura ${ }^{1,2^{*}}$, Rüdiger J. Seitz ${ }^{3}$, Hans-Ferdinand Angel ${ }^{4}$ \\ ${ }^{1}$ Institute of Development, Aging and Cancer, Tohoku University, Sendai, Japan \\ ${ }^{2}$ International Research Institute of Disaster Science, Tohoku University, Sendai, Japan \\ ${ }^{3}$ Centre for Neurology and Neuropsychiatry, LVR-Klinikum Düsseldorf, Heinrich-Heine-University Düsseldorf, \\ Düsseldorf, Germany \\ ${ }^{4}$ Institute of Catechetics and Religious Education, Karl-Franzens-University Graz, Graz, Austria \\ Email: motoaki@idac.tohoku.ac.jp
}

Received 17 November 2014; accepted 1 December 2014; published 14 January 2015

Academic Editor: Ana Adan, University of Barcelona, Spain

Copyright (C) 2015 by authors and Scientific Research Publishing Inc.

This work is licensed under the Creative Commons Attribution International License (CC BY).

http://creativecommons.org/licenses/by/4.0/

(c) (i) Open Access

\begin{abstract}
Departing from the long debates on the role of faith/belief, recent interdisciplinary research has turned to characterize the features of the psychophysical processes underlying believing. Here we review recent cognitive neuroscience models of the believing process and propose a conceptual framework that integrates current theoretical and empiric knowledge about the processes of believing. There are theories that elegantly explain believing as a self-organization process of cognitive and emotional elements. Adding to the component of self-organized belief representation, dual-component models assume a belief evaluation component, which is probably supported by the right dorsolateral prefrontal cortex (DLPFC) and explains the stability of the belief despite the changing environment. Borrowing an idea from the neural models for the mental representation of action or situation, inclusion of both perceptive and action informations as the construct of belief representation allows the intimate relationship between a specific belief and a specific range of behaviour. Furthermore, inclusion of the personal value or affective information in the representation explains the deep impact of one's emotional and physical state on the believing process. For associating perception, action, and value in a representation, the medial frontal cortex (MFC) may play a key role. Recent neuro-cognitive models of self-cognition explain the developmental origin of such a representation and the hierarchically nested structure of three levels of complexity in the representations: basic physical level, interpersonal level, and higher social level. The integrated model provides a comprehensive perspective of the believing process which suggests the importance and future directions of this interdisciplinary approach.
\end{abstract}

${ }^{*}$ Corresponding author. 


\section{Keywords}

\section{Association Learning, Believing, Credition, Delusion, Frontal Cortex, Self, Value}

\section{Introduction}

\subsection{Question of Belief}

The appreciation of the "question of belief" in the sciences is controversial. There are respectable, in-depth discussions in theology, philosophy, psychology of religion, and religious science with different focuses of interrogation. For example, one can find discussions reflecting "degrees of belief" [1]. Moreover, there is the discussion on "functions of belief" which is based on the influential Dempster-Shafer theory [2]. But simultaneously one can get also the impression of a virtual disappearance of the notion of belief in scientific discussions. This might result from the widespread spontaneous association of "belief/to believe" with religion. This association is coined by a long tradition of western thinking. Though in Antiquity (of the Western and Oriental world) the verb "to believe" (Greek: pisteuein, Latin: credere) was used in a secular as well as in a religious manner a narrow association between "belief/to believe" and "religion" was emphasized by the very influential position of apostle Paul's central doctrine of justification by faith (e.g., Galatians 2:16; Romans 3:28). Not fulfilling the law (thora) but only the faith in Christ can lead to a community with God [3] [4]. "To believe in Christ" became the most significant feature of being a Christian. Thus, Christian religion and faith also became almost insolvably linked and the noun faith (Greek: pistis, Latin: fides) could even be understood as a central Christian virtue. Since the period of the Illumination philosophers propagated the dominant role of rationality in the scientific discourse. Accordingly, there came up an increasing interest to clarify the distinction between belief and faith [5]-[8] and, respectively, the relation between "fides et ratio" (i.e.: faith and reason) [9] [10]. Even the intention to abandon completely the concept of belief has been articulated [11].

\subsection{Question of Believing}

Aiming at breaking through such a situation, several scientists from both religious and secular fields recently started to tackle the issue of believing as a verb denoting the process character rather than the mental construct of a faith/belief expressed by a noun [12]. In psychology and cognitive neuroscience, believing is an act of generating and maintaining a mental construct as real or true based on previously stored information. There is an increasing interest in understanding this mental act in terms of adaptive significance, cognitive processes, and their neural implementation in the human brain [13]-[22]. Through interdisciplinary interrogation, it has become evident the necessity of sharing the following three notions on the nature of the believing process among the relevant academic fields.

First, the believing process is tightly connected with personal relevance, which cannot be understood without the integrating perspective of both cognition and emotion. This notion is subscribed by the findings of cognitive neuroscience. Cognitive and emotional processes are partly integrated in the lateral prefrontal cortex (LPFC) and that neural activity in the LPFC can be influenced by affective variables [23]-[26]. There is also evidence that the human amygdala plays a role not only in emotion but also in higher cognition [27] [28].

Second, the believing process deals with a coherent set of knowledge that has a hierarchically organized structure. The contents of belief in daily life is not predominated by verbal propositions but composed of different classes of knowledge items including sensations, affective states, and action plans. Notably, each of these items belongs to different levels of complexity from a basic physical up to social-concept levels, and the lowerlevel belief is often the basis of a higher-level belief. This hierarchically nested structure of the levels of complexity in belief contents resembles the Russian doll "Babushka" (or "Matreshka") which is a set of many dolls with different sizes each of which accommodates one smaller one inside [29].

Finally, the believing process is a sophisticated self-organization process that has personal and social adaptive functions. The proposition "I believe" accompanies either a sense of personal certainty about the contents, or an 
intention or position towards this proposition, although the truth of the contents cannot be proven. This is in contrast with the statement "I know", as it refers to objective estimates that can be probed by others in realityin the sense of "knowledge as justified true belief" [30]. The act of believing guides behaviour in uncertain and ambiguous situations, which usually has personal or social advantage over the risk of incorrect beliefs and inappropriate behaviour. Consistent with this active adaptive nature of the believing process, beliefs have been shown to influence reasoning as well as brain activity related to reasoning [31].

\subsection{Framework of Credition}

A challenge for the interdisciplinary collaboration was the lack of a common term for the "believing process" that encompasses these three notions in everyday language or even in philosophy or cognitive science. To address this terminological challenge, a conceptual framework of “credition” was proposed [32]. The concept stems from an anthropological view on religious experiences. The term credition was coined to denote such believing processes that encompass both religious and secular beliefs.

In this framework, the term "bab" was introduced to denote a knowledge item that consists of the contents of beliefs. Each "bab” can carry specific emotional value and describes an item at any levels of complexity. The term "bab" is a meta-theoretically conceived neologism inspired by the hierarchical organization of the Babushka doll. Similarly to such a doll of different "sizes", the same contents of a "bab" can exist with different values of "mightiness", expressing the different personal relevance of the belief content. Also, the fact that the collection of "babs," or "bab-configuration," comprises a new larger "bab” can be compared to the nested structure of this doll.

The credition denotes the self-organizing character of the believing processes that consist of four different functions: enclosure function, converter function, stabilizer function, and modulator function [33]. The "enclosure function" integrates different "babs” into a coherent knowledge set ("bab-configuration”), which is now regarded as a new larger "bab”. Thus, a single small "bab” may profoundly affect the larger "babs” and, thus, behavioral consequences. The "converter function” denotes the intimate relationship between a specific belief and specific range of behaviour. For example, when in a given bab-configuration of an agent the bab "cats are divine animals" exists, then in case of a fire, the agent will be prepared to rescue the cat from the fire. The "stabilizer function" is responsible for the stability of the belief despite the functioning of the enclosure function in a changing environment. When we use the term "belief" (i.e., as noun), we ordinarily refer to this function. The "modulator function" highlights the influence of the bodily state, particularly emotion. The influence is bound to the individual state of cognitive and/or emotional development, be it conscious or unconscious.

\subsection{Purpose}

To promote this collaboration of scientists from both religious and secular fields, in this paper, we first review existing cognitive neuroscience models relevant to the believing process encompassing the three notions with the help of the credition framework. By doing this we expect to obtain a map of these independently-conceived models within the unitary multi-dimensional framework of the "question of believing".

Then integrating these models we propose a comprehensive model of processes of believing. We will argue that the process is a self-organization of the multi-layered associations of cognitive, emotional, and behavioural representations. We then point out the key issues of this model with respect to its neural basis and its potential impact on the interdisciplinary research of secular and non-secular belief formations.

\section{Review of the Existing Models}

\subsection{Believing as a Self-Organization Process}

Some theories [17] [19] explain believing as a self-organization process of human mind in a simple general principle, congruent with the enclosure function of the credition (Figure 1).

In his influential Cognitive Dissonance Theory, Festinger [17] included believing in the class of dissonance reduction processes. Accordingly, believing is to change or to add a cognitive element to reduce dissonance with or between other cognitive elements. For example, the dissonance between two ideas, a belief that people are 
New cognitive-emotional element/“bab”

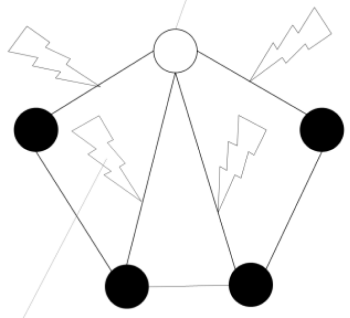

cognitive dissonance/free energy

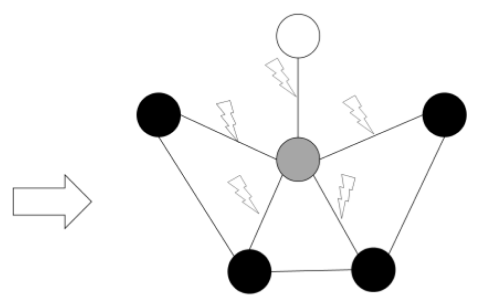

New state/bab-configuration

Figure 1. Believing as a self-organization process. From left to right: cognitive dissonance between a new cognitive/emotional element (open circle) and existing elements (closed circle), or free energy, will be reduced by a configuration change of the elements, such as by introduction of a "buffering" element (grey-filled circle).

good in general, and a knowledge that children go through a period of aggressive behaviour, is reduced by believing existence of malevolent ghosts which enter into children and cause them to do inappropriate things.

The idea of dissonance reduction appears to fit well with the explanation of human brain function in the freeenergy principle as an optimization machinery for value and its counterpart surprise [19]. Fundamental herein are the probabilistic predictions of value or reward concerning perceived information and of expected error or cost concerning future actions, which drive the system to the next state by a simple principle of reducing the free energy. Believing is one of the conscious expressions of such a self-organizing process.

\subsection{Two Components of the Believing Process}

Another simple model of the believing process is that it has two components (Figure 2). The idea is derived from the experiment of false or biased belief and observations of patients with delusional beliefs. One component is an automatic, perceptual, and representative process. Another component is a controlled, contextual, and evaluative process. It appears that the former, representative component, operates in self-organization principle (i.e., the enclosure function), and the latter, evaluative component, accommodates the stabilizer function of the credition.

Morewedge and Kahnemann [34] reviewed the experimental studies of intuitive judgment which have identified a list of systematic errors (biases) and specific models that explain these errors. Many of the models invoke a dual-process or dual-system view, in which automatic processes (System 1) generate impressions and tentative judgments, which might be accepted, blocked, or corrected by controlled processes (System 2). Morewedge and Kahnemann have identified System 1 with the automatic operations of associative memory, which sounds synonymous to self-organization or the enclosure function.

Langdon and Coltheart [20] reviewed the reports of various types of bizarre delusions, and proposed that two deficits must be present in such conditions: 1) there must be some damage to sensory and/or attention-orienting mechanisms which causes an aberrant perception-this explains the bizarre content of the causal hypothesis generated to explain what is happening. 2) There must also be a failure of belief evaluation-this explains why a hypothesis, which is implausible in the light of general common sense, is adopted as belief. Normal functioning of the latter, the belief evaluation process, is likely to filter out aberrant hypotheses that break continuity with one’s previous belief including "common sense", thus accommodating the stabilizer function.

\subsection{The Roles of Frontal Cortex}

Neuropsychological and neuroimaging studies have pointed out that the frontal cortex plays a critical role in believing. Two different approaches suggested different subareas for different interpretations. In these approaches, the right LPFC are likely candidates for the stabilizer function and the medial frontal cortex (MFC) for the converter and modulator functions.

On the one hand, Coltheart [13] [14] developed the two-component model of bizarre delusion [20] by incor- 
impression / perception / hypothesis

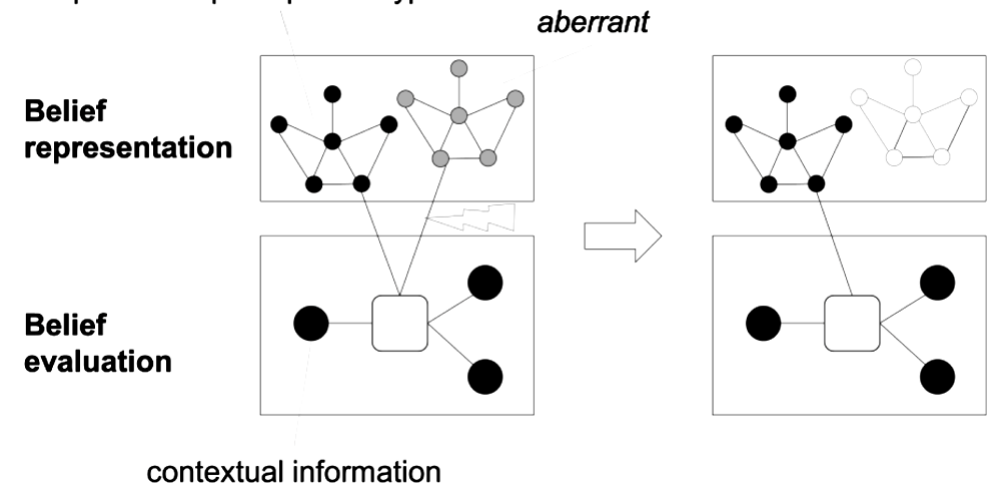

Figure 2. Dual-component model. In the belief-representation component, multiple impressions, perceptions, or hypotheses are self-organized and some of which may be aberrant in terms of contextual information gathered in the belief-evaluation component (left panel). The aberrant impressions, perceptions, or hypotheses are blocked by the belief evaluation component (right panel), the failure of which may result in an erroneous or delusional belief.

porating neuroimaging findings on patients with delusional belief and relevant activation studies with normal subjects. He suggested that the belief evaluation component is accommodated in the right LPFC based on the finding of a reduced activity in this region in delusional patients [13] [16] and on the response of this region in the face of knowledge-violating information in healthy subjects [15] [18] [22]. Considering the potential relevance of the belief evaluating process to the stability of the belief, this brain area may correspond to the stabilizer function. Accordingly, the belief representation is assumed to exist mostly in the posterior cortices, while the neural correlate of the contextual information per se is not mentioned (Figure 3(a)).

On the other hand, Seitz and Angel [21] reviewed neuroimaging studies of processes relevant to religious and secular beliefs, outside the conceptual framework of the dual-component structure of the believing process. They identified a consistent activation of the medial frontal cortex (MFC) across these studies. They were particularly interested in the value-based interactions of perceived external state (e.g., perception), internal state (e.g., emotion), and action plan within the believing process, that is, the converter and modulator functions of credition. They proposed that the MFC integrates perception, action, and emotional or value information, which are likely represented in the perception-related, action-related, and (para-) limbic cortices (Figure 3(b)).

\subsection{Cortical Belief Representations}

Neuroscience studies have addressed the neural substrate of different types of mental representation of physical and social environment, and revealed involvement of not only perceptive information but also of action information in such representations. This notion suggests that behavioural output is inherent in many types of mental representation, which can be a content of belief, thus explaining the converter function.

One prominent example is the notion of the Mirror Neuron System (MNS) whose visual-motor association system involves frontal-parietal neural circuits (Figure 3(c)). A particular feature of the MNS is that it comprises neurons that have been observed to discharge when a monkey performs a goal-directed motor act as well as when a monkey observes another individual performing the same or a similar motor act [35] [36]. By assumeing that the belief representation includes the MNS, it is feasible to explain why belief related to other's action allows efficient conversion to the believer's action plan. For example, a person who believes to be physically assaulted by someone else may immediately think of counterattacking by a similar action [37].

Another example is the concept of an "event simulator" [38] or "situated conceptualization" [39], which assumes representation of a social event or situation as association of cognitive elements that construct frequently experienced events or situations. Given that the experience of an event or situation typically includes one's behavioural output, it is included in the cognitive elements inherent in such a representation. By assuming the belief representation to be involved in this framework, it is feasible to explain why belief of a specific social situation is efficiently converted to a situation-appropriate behavioural plan. It is worth noting that the MFC is often 


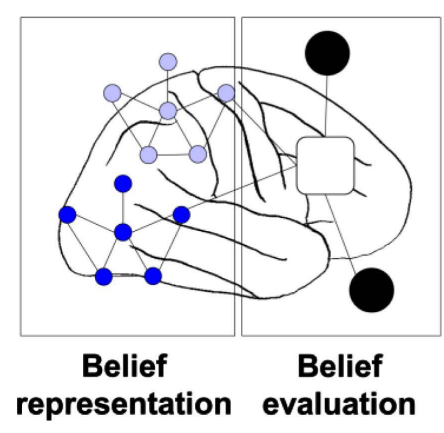

(a)

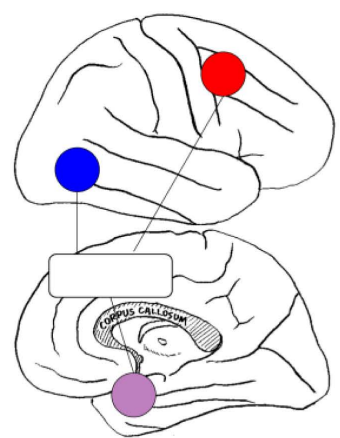

(b)

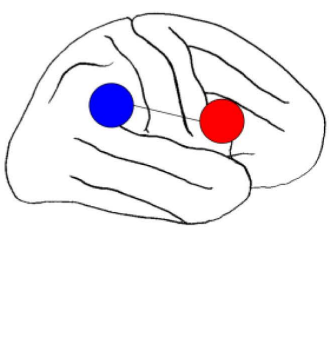

(c)

Figure 3. Role of frontal cortex and cortical belief representations. (a) Hypothetical neural basis of a dual-component model. Assumed belief representations are primarily perceptual in nature supported by posterior cortices. The belief evaluation process was assigned to the right dorsolateral prefrontal cortex (DLPFC) with the substrates of the contextual information being unspecified. Symbols used are the same as for Figure 2; (b) Based on neuroimaging studies of processes relevant to religious and secular beliefs, the medial prefrontal cortex (MFC) has been postulated to have a role in integrating perception, action, and emotional or value information likely represented in the perception-related (blue filled circle), action-related (red filled circle), and (para-) limbic cortices (purple filled circle); (c) Representation of action in the frontal-parietal Mirror Neuron System (MNS) may be a minimal belief representation involving both perceptual and action information.

assumed to have a key role in integrating the multiple cognitive elements [38] [40], consistent with the suggested role of this region in believing process [21].

\subsection{Origin of Belief Representations}

The idea of a mental representation that associates perception and action may derive a question regarding the origin of the representation; that is, how the association was initially learned.

The answer to the question is provided by the forward-prediction model of the sense of self-agency [41]; the association is learned through repeated experience of action and its consequential perception according to the Hebbian principle [42] as illustrated in Figure 4(a). The model is proposed to explain why we can have a sense of self-agency in one's action while some psychiatric patients can lose it and have the sense that their action was controlled by someone else. The sense of self-agency in action is synonymous, or at least highly related to, the very basic physical-level belief that the agent of one's action is oneself (e.g., "I am walking"). The model assumes that the sense of self-agency is derived from the match of the predicted feedback sensation as a consequence of action (e.g., somatosensory and visual) and actual sensation. The prediction of the feedback is a feedforward model of the action planning system. This is the forward modelling based on the association of action plan and feedback sensation, which is learned through repeated experience of action and feedback sensation.

The matching process of the prediction and actual sensation is usually unconscious due to the suppressive nature of the process, which may in part explain our sense of the stabilizer function. During an action, processing of feedback sensation is suppressed by the feedforward prediction, and successful suppression results in the unawareness of the consequential sensation of one's own action [41]. When there is a mismatch between the prediction and the actual sensation, the association may no longer appropriately represent the actual bodily or environmental state. In this situation, unsuccessful suppression (i.e., prediction error) results in one's surprise and the update learning of the association may occur. These dynamics appear conformal to the case of believing. One often does not care about the belief-conformal situation, while one is surprised about the belief-violating one, which may trigger the updating of the belief.

\subsection{Hierarchical Structure of Belief Representations}

Finally, we address the hierarchical structure of the belief representations. The belief contents on a basic physical level, such as "I am walking", is prerequisite to that on an interpersonal level, such as "someone is following 


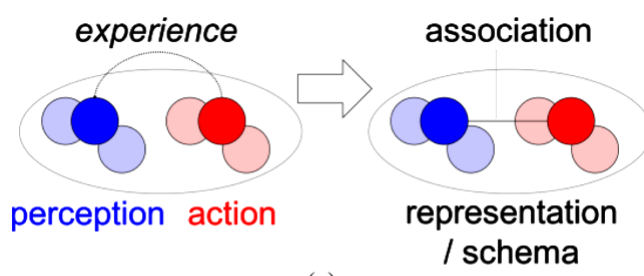

(a)

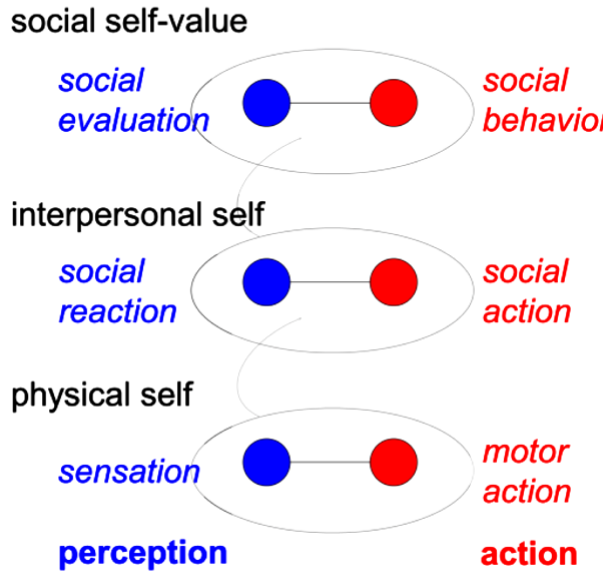

(b)

Figure 4. Associative models of self-cognition. (a) Representations involving action information and feedback perception may be acquired by association learning through repeated experience of action and its consequential perception; (b) The association of action and feedback perception, or "schema", is assumed for three hierarchical levels of the self; maturation of the schema in a lower level is prerequisite to the development of the schema in a higher level. In the physical level, schema concerns the association of motor action and its feedback sensation. The interpersonal schema associates one's social action towards the other person and the perception of other's social reaction. The social-value schema associates one's social behaviour and the perception of the evaluation in a social context.

me”. This interpersonal level content is now the basis of that on a higher social level, such as "I am such a famous person who has to get along with stalkers.” The hierarchically nested structure of the levels of complexity in belief contents, or "babs," is a critical feature of the credition framework or, specifically, the enclosure function. How is this hierarchical structure accommodated as the belief representation?

The answer to this question can be given by the recent model of self-cognition developed as an extension of the model of the sense of self-agency [43] [44]. The model is motivated for sorting out the findings in neuroimaging research on different self-related cognitive processes. In this model, the association of action and feedback perception, or "schema" (a term which has been used previously by Piaget [45]), is assumed for three different levels: physical, interpersonal, and social value (Figure 4(b)).

In the physical level, schema concerns the association of motor action and its feedback sensation; this is the very idea of the self-agency model. In addition, the model also considers the physical schema to accommodate the association of one's own motor action and the perception of other's similar action, which allows explanation of the MNS in this schema. This schema is considered to be supported by the network of sensory and motor association cortices. The interpersonal schema associates one's action towards the other person and the perception of other's response; this schema allows one to conceptualize the social relationship between the self and others, and believing on an interpersonal level, such as that "someone is following me”. The neural correlates of this schema are assumed to include the dorsomedial prefrontal cortex and temporoparietal amodal association cortices, overlapping with those of the social event simulator [38]. The social-value schema associates one's behaviour and the perception of the social evaluation by others on the behaviour; this schema is concerned with the social self-concept, such as the context-specific social self-value and social role, and allows one believing in a social-value level that "I am such a famous person who has to get along with stalkers." This schema is likely to be accommodated in midline cortical structures including the ventromedial prefrontal cortex and posterior cingulate cortex. It is assumed that the maturation of the schema in a lower level is prerequisite to the development 
of the schema in a higher level.

\section{Proposal}

\subsection{Integrated Model}

Here we present an integrated model of the believing process (Figure 5) incorporating the models reviewed so far. The self-organizing nature of the believing process was regarded as its basic principle of the system dynamics. Based on the dual-component framework (i.e., belief representation and selection), we elaborated on the internal structure of the representation component incorporating the concept of perception-action-value triad [40] into the notion of cortical representation of perception-action association, and weaving it into the hierarchical three levels [43] [44]. Then this integrated model explains all the interested features of the believing process, that is, the four functions of the credition including the hierarchically nested levels of complexity in stabilized beliefs.

The model may be most easily understood by viewing the internal structure of the belief representation along its developmental process. Infants first construct the physical-level belief representations by learning the association of one's motor action and feedback sensation, and its reward value. The maturation of the representations on this level allows one to face the primitive social environment (i.e., social interaction). Here one constructs the interpersonal-level representation by learning the association of one's social action, the other's reaction to it, and the value of this transaction. Further, the accumulation of the interpersonal-level representations enables one to reflect upon the relationship between one's own social behaviour in a specific social context and social evaluation given to it; this association comprises the belief representation at a social level. The internal structure of the belief representation explains the close association of behaviour and affective state with belief (i.e., the converter and modulator functions, respectively) and the nested hierarchy of the belief contents with different levels of complexity.

With regard to the two-component structure, the integration of in part contradicting ideas has eventually made us to expand the concept of the belief evaluation component to belief "selection" component. This component is

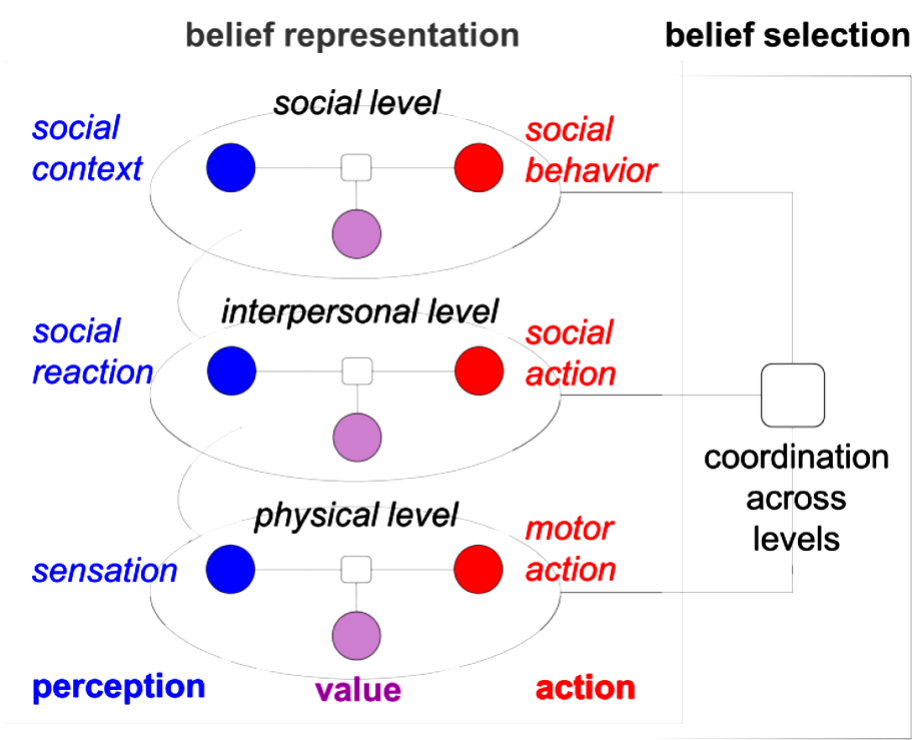

Figure 5. Integrated model of believing processes. Basic framework is a dual-component model (belief representation and selection; c.f. Figure 2 and Figure 3(a)). The internal structure of the belief representation component was elaborated by incorporating the concept of perception-action-value triad (c.f. Figure 3(b)) into the notion of cortical representation of perception-action association (c.f. Figure 3(c)), and weaving it into the hierarchical three levels (c.f. Figure 4(b)). The belief selection component was conceptually updated from the original belief evaluation component (c.f. Figure 2 and Figure 3(a)) in that it now has two processes: one corresponds to a former belief evaluation component and another overlaps with the belief representation component. The latter process includes the connecting node or an "action" and "value" element in each level of representation, which we assumed to play a key role in belief generation within a level of representation. 
an executive or productive part of the believing process and assumed to have two processes: one corresponds to former belief evaluation component [20] and another overlaps with the belief representation component. The latter process includes the connecting node or an "action" and "value” element in each level of representation, which we assumed to play a key role in belief generation within a level of representation; this idea is within the framework of believing in perception-action-value triad [21]. The former process (i.e., former belief evaluation component) is assumed to coordinate potentially conflicting beliefs across levels. The dissociation of the two different believing processes is demonstrated by the case of delusional belief [20]. In a self-misidentification case, for example, a patient believes and insists that the person in the mirror is not the self but is another person, while in other occasions combing him or herself using a mirror without any trouble. The patient believes that the person in the mirror is the self at a physical level that is why he or she can comb. At an interpersonal level, however, he or she believes that the person is another person. The belief-generation process may be intact and resulted belief is "correct" within each level, but as an individual, the patient fail at coordinating two conflicting beliefs. It appears that the belief-generation process is primarily governed by a self-organization principle, therefore mainly concerns the enclosure function. In contrast, the across-level coordination process explains our integrity as an individual across representation levels and why our believing process rarely goes "very wrong”, that is, the stabilizer function.

\subsection{Issues on Neural Mechanism}

In spite of the rich neuropsychological and neuroimaging evidence of the involvement of cortical and subcortical structures in the cognitive and affective processes relate to the believing process, the assignment of these structures, particularly frontal cortices, to a specific component, process, or element of the model is a future issue.

One important issue is the role of MFC, which is assumed to comprise a belief-representation component, as well as the belief-generation process of the belief-selection component. The involvement of distinct functional sub-regions of the medial frontal cortex in three levels of belief representations seems to agree with Seitz [46] and Sugiura [44]: the posterodorsal, anterodorsal, and ventral part of the cortex are likely to contribute to the physical, interpersonal, and social levels, respectively. However, they assume different roles of this cortex in the belief representation. Seitz and Angel [21] speculated that the medial frontal cortex, and in particular the preSMA, is a connecting node that associates perception, action, and the attributed value, which all are represented in other structures of a widespread cerebral network. On the other hand, Sugirua [44] assumed that this region, as well as other frontal regions, represents action element. While both views are primarily based on neuroimaging findings during top-down or bottom-up (e.g., conflict- or error-induced) attention, it is difficult to segregate element and associating node from such findings because activation is expected in the neural correlates of all the elements and node. Neuropsychological assessment of patients with a brain lesion or virtual brain lesions induced by transcranial magnetic stimulation [47] in healthy subjects may help resolving this controversy [48] [49]. On the other hand, however, it is also possible to render this controversy insubstantial given the inherence of an action generating process in the believing process (i.e., converter function of the credition).

The functional segregation of the right LPFC is also an important issue. Although several neuroimaging papers have showed activation in the right LPFC during tasks that require belief evaluation or related cognitive control, activated regions vary considerably [15] [18] [22] [50] [51]. It has been hypothesized that the LPFC areas dedicated to the different levels of hierarchically organized cognitive control are laid out in the rostro-caudal axis; posterior-to-anterior PFC mediates progressively abstract, higher-order control [52] [53]. It is tempting to compare the hierarchical layers of belief representation in the current model and the hierarchical organization of the cognitive control in the right LPFC with an eye to the future update of the model.

\subsection{Impact on Interdisciplinary Science of Believing}

The integrated model provides this interdisciplinary scientific field a new perspective such that the believing process might be understood as an adaptive adjustment process which structures the interference of the inner representations and probabilistic estimates of the outside world according to a personal valuation matrix. That is, the self-organization dynamics in the perception-action-value triad predicts the believing process as a personal cognitive-emotional function. Due to the equivalence of selecting belief and selecting action, it is expected that one believes according to a more congruent correspondence to the personal valuation processes [40] [54]. Owing to the involvement of social value at the social level belief representation and at the across-level coordina- 
tion process, however, the dynamics is likely to be biased to beliefs that are held in the society or culture we live in.

In traditional perspectives, the factual contents of a belief have been assumed to be explicit and static. In contrast, the current perspective provides support for the position that believing processes are fluent and typically subconscious as they are inherent in the rapidly achieved probabilistic interpretations of the complex world in personal terms [54]. This pertains to perception of physical objects and events in the environment, to interpreting other people's intentions from their body movements and behaviour, and to comprehending the meaning of verbal material in open speech and the literature. Further, these formal or abstract interpretations are to be put in register with inner valuations, emotions, and even the introception of the bodily state of the given person. These processes take place in the order of milliseconds, are thus not accessible to conscious awareness and engage multimodal networks of the human brain at different levels of organization. Accordingly, to unravel their functioning, generation of testable hypotheses addressing aspects of the believing processes and investigation of their implementation in the human brain would be promising.

The current perspective may provide explanation for the reason why the question of belief was ill-posed and nourished a general underestimation of the role of believing in individuals and societies. The explicit focus on the question of the process of believing has the potential for understanding its function and physiological role. In the current perspective, believing is an inherent part of behavioural planning in a sense that the definition of the dependent variables representing the environment or situation is prerequisite to determination of the independent variable of the action that one takes, or vice versa. This dynamic aspect is essential for asking the question of belief contents. It can be revealed only by questioning the processes of believing.

\section{Acknowledgements}

MS is supported by MEXT KAKENHI (25560347).

\section{References}

[1] Huber, F. and Schmidt-Petri, C. (2009) Degrees of Belief. Vol. 342, Springer, Heidelberg. http://dx.doi.org/10.1007/978-1-4020-9198-8

[2] Denoeux, T. and Masson, M.H. (2012) Belief Functions: Theory and Applications. Vol. 164, Springer, Heidelberg. http://dx.doi.org/10.1007/978-3-642-29461-7

[3] Aune, D.E. (2013) Recent Readings of Paul Relating to Justification by Faith. In: Aune, D.E., Ed., Jesus, Gospel Tradition and Paul in the Context of Jewish and Greco-Roman Antiquity, Collected Essays II, Mohr, Tübingen, 472-523.

[4] Marguerat, D. (2013) The Pauline Gospel of Justification of Faith. In: Marguerat, D., Ed., Paul in Acts and Paul in His Letters, Mohr, Tübingen, 179-219.

[5] Kenny, A. (1992) What Is Faith?: Essays in the Philosophy of Religion. Oxford University Press, Oxford.

[6] Mitchell, B. (1994) Faith and Criticism: The Sarum Lectures 1992. Oxford University Press, Oxford.

[7] Smith, W.C. (1987) Faith and Belief. Princeton University Press, Princeton.

[8] Swinburne, R. (1983) Faith and Reason. Oxford University Press, Oxford.

[9] Helm, P. (1999) Faith and Reason. Oxford University Press, Oxford.

[10] Plantinga, A. and Wolterstorff, N. (1983) Faith \& Rationality: Reason \& Belief in God. University of Notre Dame Press, Notre Dame.

[11] Stich, S. (1985) From Folk Psychology to Cognitive Science: The Case against Belief. MIT Press, Cambridge.

[12] Runehov, A.L.C. and Angel, H.F. (2013) The Process of Believing: Revisiting the Problem of Justifying Beliefs. Studies in Science and Theology, 14, 205-218.

[13] Coltheart, M. (2007) The 33rd Sir Frederick Bartlett Lecture-Cognitive Neuropsychiatry and Delusional Belief. Quarterly Journal of Experimental Psychology, 60, 1041-1062. http://dx.doi.org/10.1080/17470210701338071

[14] Coltheart, M. (2010) The Neuropsychology of Delusions. Annals of the New York Academy of Sciences, 1191, 16-26. http://dx.doi.org/10.1111/j.1749-6632.2010.05496.x

[15] Corlett, P.R., Aitken, M.R.F., Dickinson, A., Shanks, D.R., Honey, G.D., Honey, R.A.E., Robbins, T.W., Bullmore, E.T. and Fletcher, P.C. (2004) Prediction Error during Retrospective Revaluation of Causal Associations in Humans: fMRI Evidence in Favour of an Associative Model of Learning. Neuron, 44, 877-888. http://dx.doi.org/10.1016/j.neuron.2004.11.022 
[16] Devinsky, O. (2009) Delusional Misidentifications and Duplications Right Brain Lesions, Left Brain Delusions. Neurology, 72, 80-87. http://dx.doi.org/10.1212/01.wnl.0000338625.47892.74

[17] Festinger, L.A. (1957) Theory of Cognitive Dissonance. Stanford University Press, Stanford.

[18] Fletcher, P.C., Anderson, J.M., Shanks, D.R., Honey, R., Carpenter, T.A., Donovan, T., Papadakis, N. and Bullmore, E.T. (2001) Responses of Human Frontal Cortex to Surprising Events Are Predicted by Formal Associative Learning Theory. Nature Neuroscience, 4, 1043-1048. http://dx.doi.org/10.1038/nn733

[19] Friston, K. (2010) The Free-Energy Principle: A Unified Brain Theory? Nature Reviews Neuroscience, 11, $127-138$. http://dx.doi.org/10.1038/nrn2787

[20] Langdon, R. and Coltheart, M. (2000) The Cognitive Neuropsychology of Delusions. Mind \& Language, 15, $184-218$. http://dx.doi.org/10.1111/1468-0017.00129

[21] Seitz, R.J. and Angel, H.F. (2012) Processes of Believing-A Review and Conceptual Account. Reviews in the Neurosciences, 23, 303-309. http://dx.doi.org/10.1515/revneuro-2012-0034

[22] Turner, D.C., Aitken, M.R.F., Shanks, D.R., Sahakian, B.J., Robbins, T.W., Schwarzbauer, C. and Fletcher, P.C. (2004) The Role of the Lateral Frontal Cortex in Causal Associative Learning: Exploring Preventative and Super-Learning. Cerebral Cortex, 14, 872-880. http://dx.doi.org/10.1093/cercor/bhh046

[23] Cabeza, R. and Nyberg, L. (2000) Imaging Cognition II: An Empirical Review of 275 PET and fMRI Studies. Journal of Cognitive Neuroscience, 12, 1-47. http://dx.doi.org/10.1162/08989290051137585

[24] Decety, J. and Chaminade, T. (2003) Neural Correlates of Feeling Sympathy. Neuropsychologia, 41, 127-138. http://dx.doi.org/10.1016/S0028-3932(02)00143-4

[25] Gray, J.R., Braver, T.S. and Raichle, M.E. (2002) Integration of Emotion and Cognition in the Lateral Prefrontal Cortex. Proceedings of the National Academy of Sciences of the United States of America, 99, 4115-4120. http://dx.doi.org/10.1073/pnas.062381899

[26] Seitz, R.J., Schafer, R., Scherfeld, D., Friederichs, S., Popp, K., Wittsack, H.J., Azari, N.P. and Franz, M. (2008) Valuating Other People's Emotional Face Expression: A Combined Functional Magnetic Resonance Imaging and Electroencephalography Study. Neuroscience, 152, 713-722. http://dx.doi.org/10.1016/j.neuroscience.2007.10.066

[27] Rolls, E.T. (2006) Brain Mechanisms Underlying Flavour and Appetite. Philosophical Transactions of the Royal Society B: Biological Sciences, 361, 1123-1136. http://dx.doi.org/10.1098/rstb.2006.1852

[28] Schaefer, A. and Gray, J.R. (2007) A Role for the Human Amygdala in Higher Cognition. Reviews in the Neurosciences, 18, 355-363. http://dx.doi.org/10.1515/revneuro.2007.18.5.355

[29] Angel, H.F. (2015) Die Creditive Basis wirtschaftlichen Handelns. Zur wirtschaftsanthropologischen Bedeutung von Glaubensprozessen. In: Dierksmeier, C., Hemel, U. and Manemann, J., Eds., Wirtschaftsanthropologie, NOMOS, Baden-Baden.

[30] Gettier, E.L. (1963) Is Justified True Belief Knowledge? Analysis, 23, 121-123. http://dx.doi.org/10.1093/analys/23.6.121

[31] Goel, V. and Dolan, R.J. (2003) Explaining Modulation of Reasoning by Belief. Cognition, 87, B11-B22. http://dx.doi.org/10.1016/S0010-0277(02)00185-3

[32] Angel, H.F. (2006) Religiosität als menschliches Potential. Ein anthropologisches Modell im neurowissenschaftlichen Horizont. In: Angel, H.F., Broking-Bortfeldt, M., Hemel, U., Kunstmann, J., Jakobs, M., Pirner, M.L. and Rothgangel, M., Eds., Religiosität, Kohlhammer, Stuttgart, 62-89.

[33] Angel, H.F. (2013) Credition, the Process of Belief. In: Runehov, A.L.C. and Oviedo, L., Eds., Encyclopedia of Sciences and Religions, Springer, Dordrecht, 536-539. http://dx.doi.org/10.1007/978-1-4020-8265-8 1565

[34] Morewedge, C.K. and Kahneman, D. (2010) Associative Processes in Intuitive Judgment. Trends in Cognitive Sciences, 14, 435-440. http://dx.doi.org/10.1016/j.tics.2010.07.004

[35] Nelissen, K., Borra, E., Gerbella, M., Rozzi, S., Luppino, G., Vanduffel, W., Rizzolatti, G. and Orban, G.A. (2011) Action Observation Circuits in the Macaque Monkey Cortex. Journal of Neuroscience, 31, 3743-3756. http://dx.doi.org/10.1523/JNEUROSCI.4803-10.2011

[36] Rizzolatti, G., Fogassi, L. and Gallese, V. (2001) Neurophysiological Mechanisms Underlying the Understanding and Imitation of Action. Nature Reviews Neuroscience, 2, 661-670. http://dx.doi.org/10.1038/35090060

[37] Zamboni, G., Gozzi, M., Krueger, F., Duhamel, J.R., Sirigu, A. and Grafman, J. (2009) Individualism, Conservatism, and Radicalism as Criteria for Processing Political Beliefs: A Parametric fMRI Study. Social Neuroscience, 4, 367-383. http://dx.doi.org/10.1080/17470910902860308

[38] Krueger, F., Barbey, A.K. and Grafman, J. (2009) The Medial Prefrontal Cortex Mediates Social Event Knowledge. Trends in Cognitive Sciences, 13, 103-109. http://dx.doi.org/10.1016/j.tics.2008.12.005

[39] Barsalou, L.W. (2009) Simulation, Situated Conceptualization, and Prediction. Philosophical Transactions of the Royal 
Society B: Biological Sciences, 364, 1281-1289. http://dx.doi.org/10.1098/rstb.2008.0319

[40] Seitz, R.J., Franz, M. and Azari, N.P. (2009) Value Judgments and Self-Control of Action: The Role of the Medial Frontal Cortex. Brain Research Reviews, 60, 368-378. http://dx.doi.org/10.1016/j.brainresrev.2009.02.003

[41] Frith, C.D., Blakemore, S.J. and Wolpert, D.M. (2000) Abnormalities in the Awareness and Control of Action. Philosophical Transactions of the Royal Society B: Biological Sciences, 355, 1771-1788. http://dx.doi.org/10.1098/rstb.2000.0734

[42] Hebb, D.O. (1949) The Organization of Behaviour. Wiley \& Sons, New York.

[43] Sugiura, M. (2011) The Multi-Layered Model of Self: A Social Neuroscience Perspective. In: Kawashima, R., Sugiura, M. and Tsukiura, T., Eds., New Frontiers in Social Cognitive Neuroscience, Tohoku University Press, Sendai, 111135.

[44] Sugiura, M. (2013) Associative Account of Self-Cognition: Extended Forward Model and Multi-Layer Structure. Frontiers in Human Neuroscience, 7, 535. http://dx.doi.org/10.3389/fnhum.2013.00535

[45] Piaget, J. (1928) The Child's Conception of the World. Routledge and Kegan Paul, London.

[46] Seitz, R.J., Nickel, J. and Azari, N.P. (2006) Functional Modularity of the Medial Prefrontal Cortex: Involvement in Human Empathy. Neuropsychology, 20, 743-751. http://dx.doi.org/10.1037/0894-4105.20.6.743

[47] Walsh, V. and Rushworth, M. (1999) A Primer of Magnetic Stimulation as a Tool for Neuropsychology. Neuropsychologia, 37, 125-135.

[48] Klucharev, V., Munneke, M.A.M., Smidts, A. and Fernandez, G. (2011) Downregulation of the Posterior Medial Frontal Cortex Prevents Social Conformity. Journal of Neuroscience, 31, 11934-11940. http://dx.doi.org/10.1523/JNEUROSCI.1869-11.2011

[49] Rushworth, M.F.S., Hadland, K.A., Paus, T. and Sipila, P.K. (2002) Role of the Human Medial Frontal Cortex in Task Switching: A Combined fMRI and TMS Study. Journal of Neurophysiology, 87, 2577-2592.

[50] Sakai, K. and Passingham, R.E. (2003) Prefrontal Interactions Reflect Future Task Operations. Nature Neuroscience, 6, 75-81. http://dx.doi.org/10.1038/nn987

[51] Sugiura, M., Friston, K.J., Willmes, K., Shah, N.J., Zilles, K. and Fink, G.R. (2007) Analysis of Intersubject Variability in Activation: An Application to the Incidental Episodic Retrieval during Recognition Test. Human Brain Mapping, 28, 49-58. http://dx.doi.org/10.1002/hbm.20256

[52] Badre, D. (2008) Cognitive Control, Hierarchy, and the Rostro-Caudal Organization of the Frontal Lobes. Trends in Cognitive Sciences, 12, 193-200. http://dx.doi.org/10.1016/j.tics.2008.02.004

[53] Koechlin, E. and Summerfield, C. (2007) An Information Theoretical Approach to Prefrontal Executive Function. Trends in Cognitive Sciences, 11, 229-235. http://dx.doi.org/10.1016/j.tics.2007.04.005

[54] Seitz, R.J. and Angel, H.F. (2014) Psychology of Religion and Spirituality: Meaning-Making and Processes of Believing. Religion, Brain \& Behaviour, 22-30. http://dx.doi.org/10.1080/2153599X.2014.891249 
Scientific Research Publishing (SCIRP) is one of the largest Open Access journal publishers. It is currently publishing more than 200 open access, online, peer-reviewed journals covering a wide range of academic disciplines. SCIRP serves the worldwide academic communities and contributes to the progress and application of science with its publication.

Other selected journals from SCIRP are listed as below. Submit your manuscript to us via either submit@scirp.org or Online Submission Portal.
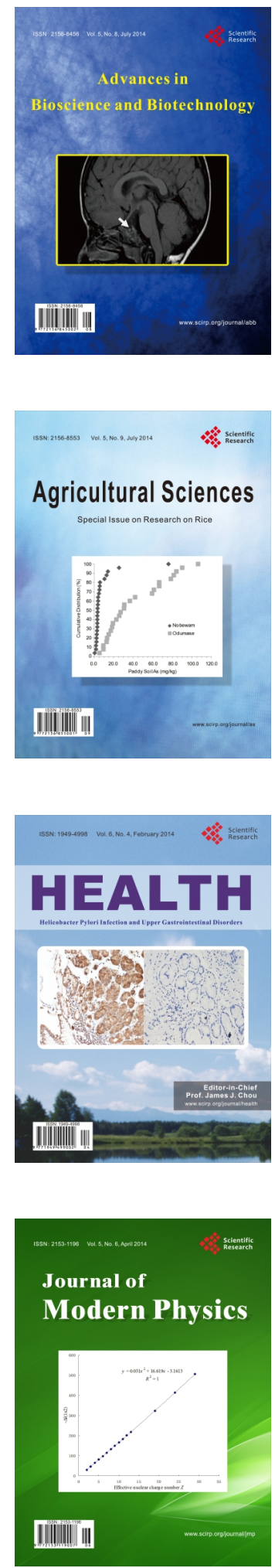
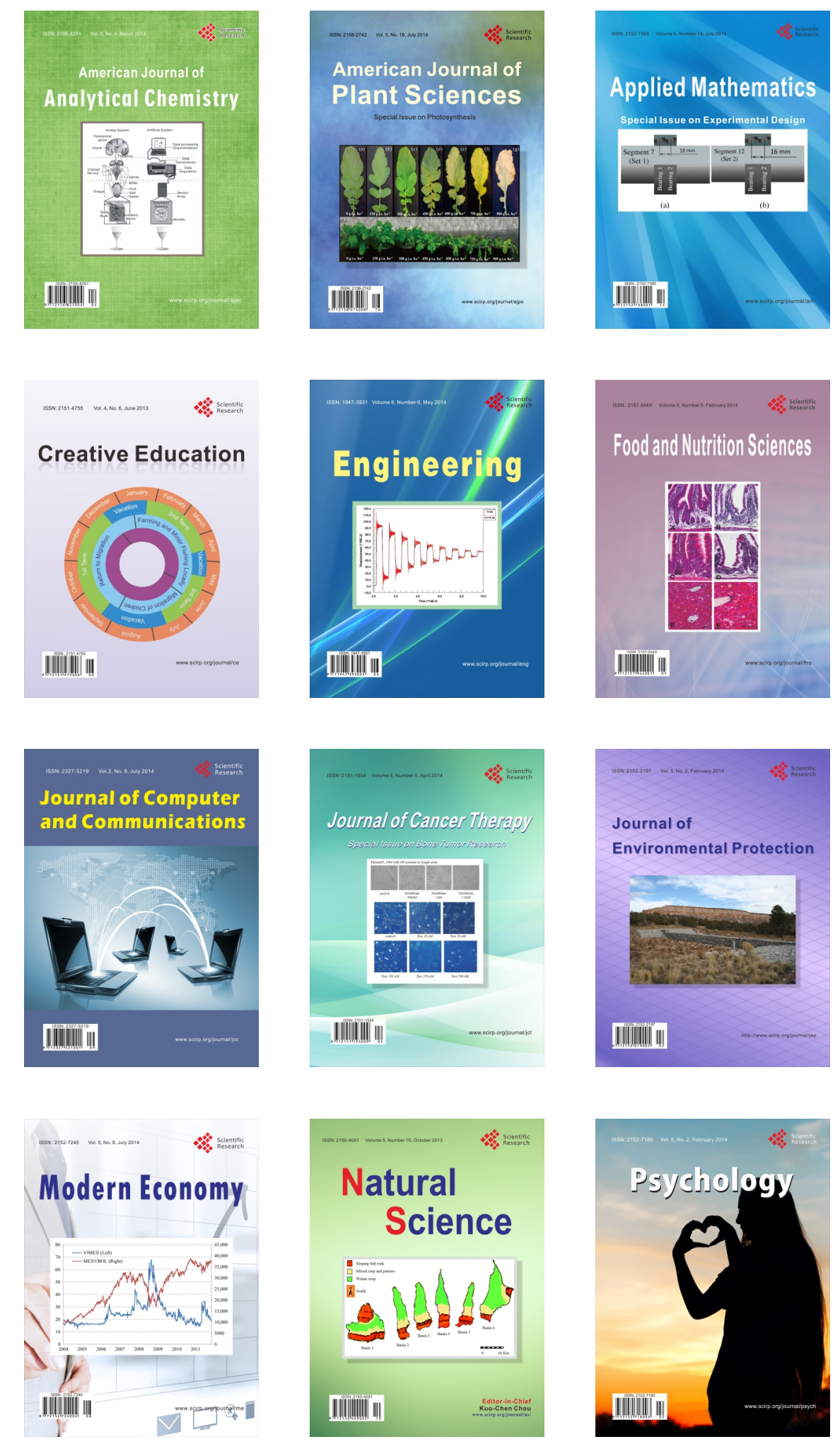